\title{
Apedicitis aguda asociada a mucocele apendicular y tumor carcinoide
}

\section{Reporte de un caso y revisión bibliográfica}

Rivera-Barragán $V^{*}$, Flores-Álvarez E**, Méndez-Esparza AG ${ }^{* * *}$, Pedroza-Herrera GH***

\section{Resumen}

Se presenta el caso de un paciente masculino de 16

años que fue sometido a apendicentomía encontrando

- además mucocele y por estudio histopatológico un tu-

- mor carcinoide. Esta asociación tiene una prevalencia

baja. Se hace además la revisión de la literatura. El seguimiento del paciente a los dos años es satisfactoria. LUXMÉDICA 6(19): 35-39

Palabras clave. Mucocele, apendicitis aguda, tumor carcinoide.

\section{Introducción}

La apendicitis aguda es la inflamación del apéndice cecal y ocupa el primer lugar como causa de cirugía de urgencia en el mundo. Tiene como causa más frecuente la obstrucción de su luz que generalmente es por hiperplasia linfoide secundaria a las infecciones virales, bacterianas o tuberculosis; y por fecalitos, parásitos, cuerpos extraños, semillas, adherencias y tumores ${ }^{1}$.

* Cirujano General, Profesor Investigador Departamento de Cirugía Universidad Autónoma de Aguascalientes, Hospital Star Médica, Aguascalientes

** Cirujano General, Cirujano Oncólogo, Maestro en Ciencias Médicas, Centenario Hospital Miguel Hidalgo, Hospital Star Médica, Aguascalientes

*** Médico Cirujano, Profesor Investigador Departamento de Cirugía Universidad Autónoma de Aguascalientes, Hospital Star Médica, Aguascalientes

**** Médico Anatomo-patólogo Hospital General ISSSTE, Aguascalientes

Fecha de recibido 27 de mayo 2011

Fecha de aceptación 20 de agosto 2011

Correspondencia Dr Virgilio Rivera Barragán. Departamento de Cirugía del Centro de Ciencias de la Salud, Universidad Autónoma de Aguascalientes, Av Universidad \#940 CP 20100. Teléfono 9108430. Correo electrónico virgi_rivera@yahoo.com.mx 


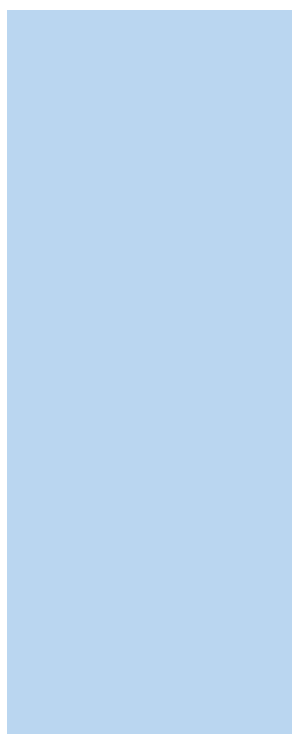

El mucocele consiste en una dilatación quística del apéndice vermiforme por la acumulación de material mucoso, ocasionado por la obstrucción del lumen apendicular a nivel de su base. Su frecuencia es muy baja, sin un cuadro clínico característico y que puede ser benigno o maligno².

El tumor carcinoide se refiere a tumores neuroendócrinos que se encuentran a lo largo del tracto gastrointestinal, derivan de las células de Kulchitsky localizadas en las criptas de Lieberkuhn. Se clasifican de acuerdo al sitio de origen y al grado de diferenciación. La presentación clínica de estos tumores depende del sitio primario donde se encuentran y pueden ser un hallazgo incidental ${ }^{3}$. El sitio más frecuente de tumor carcinoide gastrointestinal es el apéndice cecal, y son raros los síntomas atribuibles a él, a menos que ocluya la luz apendicular y provoque apendicitis aguda. La asociación con mucocele es infrecuente ${ }^{4}$. El tratamiento es quirúrgico aunque pueden responder a quimioterapia.

\section{Presentación del caso}

Paciente masculino de 16 años de edad con secuelas de parálisis cerebral infantil. Acude al servicio de Urgencias por dolor abdominal de doce horas de evolución que inició en el epigastrio y migró a la fosa ilíaca derecha en el transcurso de cuatro horas. Se acompañó de náuseas y vómito en dos ocasiones. A la exploración física se encuentra con dolor en fosa ilíaca derecha y signos clínicos de apendicitis aguda: Mc Burney, Rovsing, psoas, obturador y descompresión positivos. Los exámenes de laboratorio muestran leucocitosis de 16 000, 90\% de segmentados y 5\% de bandas; 350000 plaquetas. Las radiografías de abdomen muestran asa fija en fosa ilíaca derecha y borramiento del tercio inferior del psoas derecho. Con el diagnóstico de apendicitis aguda se somete a apendicectomía abierta. Los hallazgos consistieron en mucocele apendicular de $8 \mathrm{~cm}$, el apéndice inflamado y con natas fibrinopurulentas. El estudio histopatológico reveló apendicitis aguda supurada, peritonitis aguda y tumor carcinoide del apéndice cecal, con bordes quirúrgicos libres de tumor. La evolución postquirúrgica es buena. A los dos años de vigilancia, el paciente se encuentra asintomático y sin datos de recidiva.

\section{Discusión}

Típicamente el cuadro de apendicitis aguda se inicia con dolor continuo de intensidad moderada en epigastrio o en la parte central abdominal seguido por anorexia, náusea y vómito. En las siguientes tres a seis horas, el dolor tiende a localizarse hacia el cuadrante inferior derecho del abdomen. La fiebre moderada sugiere la posible presencia de complicaciones. Una vez que se establece el diagnóstico de apendicitis aguda el tratamiento es quirúrgico, sea abierto o laparoscópico, y debe de efectuarse a la brevedad posible, en cuanto las condicio- 
nes generales de salud del paciente lo permitan, enfatizando que las complicaciones están en relación directa con el retraso en la intervención".

Mucocele es un término netamente descriptivo, utilizado en forma genérica para referir dilatación obstructiva de la luz apendicular debida a la acumulación anormal de moco $^{2}$ ya que la etiología puede ser benigna (hiperplasia, adenoma u obstrucción) o maligna (adenocarcinoma, carcinoide). El diagnóstico de certeza sólo puede establecerse a través del estudio histopatológico ${ }^{5}$. La frecuencia de las neoplasias del apéndice es bastante baja, comprende el $0.2 \%$ de todas las apendicectomías y constituye una entidad clínica rara de difícil diagnóstico. Son hallazgos incidentales debido a la ausencia o inespecificidad de los síntomas ${ }^{6}$, reflejo de la asociación con la distensión o inflamación del apéndice. ${ }^{7}$

Debido a la rareza de la enfermedad no es considerada dentro de los problemas agudos de la fosa ilíaca derecha ${ }^{8}$. Los principales signos y síntomas que orientan a realizar la apendicectomía son la presencia de dolor abdominal (27\%), masa abdominal $(16 \%)$ y pérdida de peso $(10 \%)$. Como la mayoría de los mucoceles son asintomáticos y se encuentran durante una cirugía por apéndice inflamado, se requiere siempre de un estudio histopatológico?.

Las afecciones malignas apendiculares son extremadamente raras. El diagnóstico de cáncer apendicular se establece en el 0.9 a $14 \%$ de los especímenes estudiados. El tumor carcinoide apendicular es el segundo tipo histológico encontrado (33\% de los casos), después del adenocarcinoma mucinoso (37\% de los casos informados).

El primer caso de carcinoide fue descrito por Glazenbrook en 1895, y fue un tumor de la base apendicular. En 1907, Obendorfer Sen Sigfried definió un tumor que se parecía mucho al adenocarcinoma, cuyo comportamiento era más benigno ${ }^{10}$. El término diminutivo "Karzinoid" fue introducido en la reunión del 1907 de la Sociedad de Patología Alemana en Dresde, para significar la apreciación de un curso clínico y biológico más benigno de las lesiones de este tipo que las del adenocarcinoma. El promedio de edad al momento del diagnóstico de un tumor carcinoide es de 54 años, con un rango desde los 10 hasta los 93 años. La sobrevida desde el momento del diagnóstico es de 57 meses en promedio ${ }^{11,12}$

Los tumores carcinoides son una enfermedad maligna originada en las células enterocromafines, que producen sustancias vasoactivas como serotonina (5 hidroxitriptamina), bradicininas e histamina entre otras. Secundario a la producción de estas células se presenta el síndrome carcinoide. Hay tres sitios principales de origen: 1) tubo digestivo proximal, donde suelen ser altamente metastásicos; 2) tubo digestivo medio son los más frecuentemente asociados a síndrome carcinoide y 3) los originados en el tubo digestivo distal, que se asocian a una evolución más benigna ${ }^{13}$.

El tumor carcinoide se clasifica, de acuerdo a su patrón histológico, en insular, el de mejor pronóstico; trabecular; glandular o indiferenciado, el de peor pronóstico; mixto y tubular.

Los estadios, o etapas del tumor, de acuerdo al programa del SEER (Surveillance, Epidemiology and End Results) son tres:

1) Local, si la lesión está confinada al órgano de origen

2) Regional, si la invasión está extendida más allá de los límites del órgano de origen, directamente en los órganos que le rodean o tejido de los nódulos linfáticos o ambos

3) Distante, neoplasia que se disemina a otras partes del cuerpo a partir del tumor primario, ya sea por extensión directa o por diseminación metastásica, $10,{ }^{14-16}$ si no se puede establecer la información o no es suficiente para asignar un estadio, se le denomina no establecida. ${ }^{10,16}$ El mejor indicador del 
pronóstico y la malignidad va a ser la evidencia del crecimiento invasor y la presencia o ausencia de metástasis regionales o distantes ${ }^{16}$.

\section{Conclusiones}

Las afecciones malignas del apéndice son extremadamente raras, y sólo en contadas ocasiones se sospechan estos tumores antes de la intervencción quirúrgica, y menos del $50 \%$ de ellos se diagnostican durante la operación. El apéndice es el sitio más común de carcinoide gastrointestinal, seguido del intestino delgado y recto. El síndrome carcinoide rara vez se vincula con carcinoide apendicular, a menos que existan metástasis diseminadas, que ocurren en $2.9 \%$ de los pacientes. Son raros los síntomas atribuibles de forma directa al carcinoide, aunque en ocasiones el tumor puede obstruir la luz apendicular y causar apendicitis. Casi todos los carcinoides se encuentran en la punta del apéndice, y su potencial maligno se relaciona con el tamaño del tumor.

El tratamiento casi nunca requiere más que una apendicectomía simple. Sin embargo, en los tumores menores de $1 \mathrm{~cm}$ que además se extienden al mesoapéndice, y en todos los tumores mayores de $1.5 \mathrm{~cm}$ debe efectuarse una hemicolectomía derecha ${ }^{17}$.

La asociación de carcinoide, mucocele y apendicitis aguda es anecdótica,pues se requiere que se conjunten varios factores para que se pueda ocluir el apéndice y presentarse la enfermedad aguda. Sin embargo ante la presencia de un mucocele deberá realizarse una disección amplia del mesoapéndice para incluir todos los gánglios linfáticos apendiculares y realizar siempre estudio histopatológico a la pieza resecada, con la finalidad de identificar tumores y límites quirúrgicos de éstos.

La hemicolectomía derecha se reserva para los casos en que los límites quirúrgicos son positivos a tumor ${ }^{17}$.

\section{Bibliografía}

1. Rebollar GR, García AJ, Trejo TR. Apendicitis Aguda. Rev hosp Jua Mex 2009; 76(4):210-216

2. Flores $A E$, Villegas $M A$, Rivera BV, Rolón PA. Mucocele Apendicular. Lux médica 2008; 3(8):31-33

3. Eggenberger JC. Clinics in Colon \& Rectal Surgery. Uncommon Colorectal Neoplasms. 2011; 24 (3):129-134

4. Brunicardi FC, Schwartz Principios de Cirugía

5. Kasim AB y cols. Surg Laparosc Endosc Percutan Tech. 2006;16(5): 347-348

6. Valerio UJ y cols. Mucocele gigante del apéndice cecal: reporte de un caso y revisión breve. Médica Sur, 2007; 14(2):71-74

7. Bahena AJ y cols. Rev Hosp Gral Dr. M Gea González 2007; 8(1):34-36

8. Tsutsumi Y y cols. Mucocele apendicular. Hallazgo por ultrasonido. Gac Med Mex 2003. 139 (2):169-170

9. Harris R. Mucinous cystadenoma of the appendix. Ultrasound Quarterly. SRU 2005; 21(2)
10. Modlin IM, Sandor A. An analysis of 8,305 cases of carcinoid tumors. Cancer 1997; 79: 813-29.

11. Carcinoid heart disease. Curr Probl Surg 1989; 26(12):835-885.

12. Shaw PA. The topographical and age distributions of neuroendocrine cells in the normal human appendix. J Pathol 1991; 164: 235-239.

13. Narváez R et al Síndrome carcinoide: reporte de un caso con afección cardiaco y tumor primario de ovario Gac Méd Méx 2001; 137 (6): 583-587

14. Obendorfer S. Karzinoide Tumoren des Dünndarms. Frankf Zschr Pathol 1907; 1: 426-430.

15. Williams ED, Sandler M. The classification of carcinoid tumors. Lancet 1963; 1: 238-239.

16. Sandor A, Modlin IM. A retrospective analysis of 1570 appendiceal carcinoids. Am J Gastroenterol 1998; 93: 422-428

17. Bernard MJ, Berger DH. Apéndice. En Schwartz principios de cirugía 9a ed. Barcelona: Mc Graw Hill; 2006. P.1088 


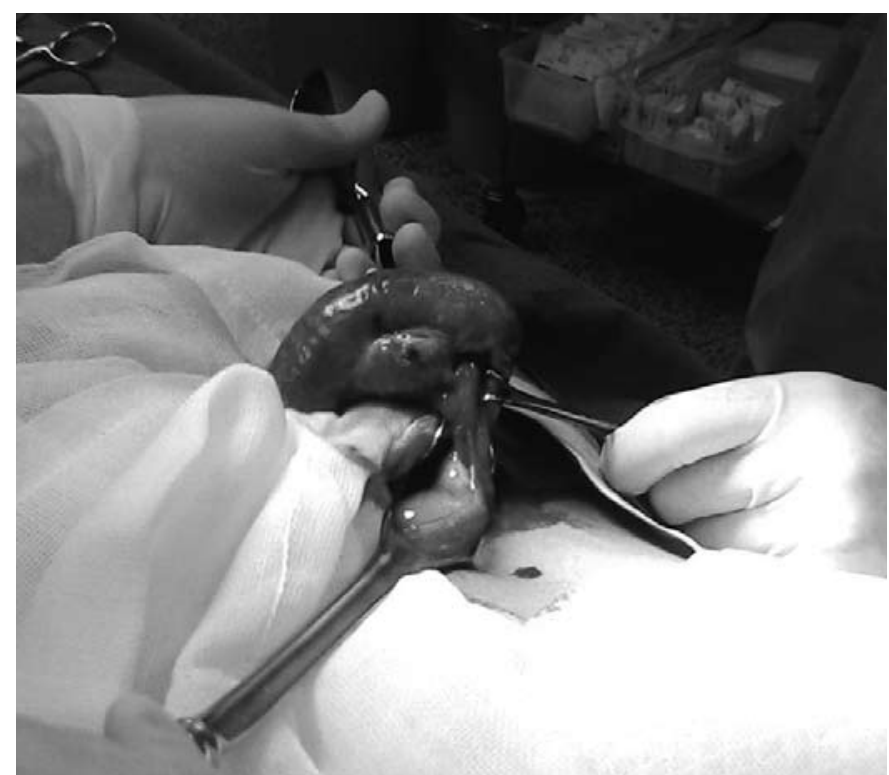

Fig. 1 Apéndice distendido, con mucocele y datos de inflamación

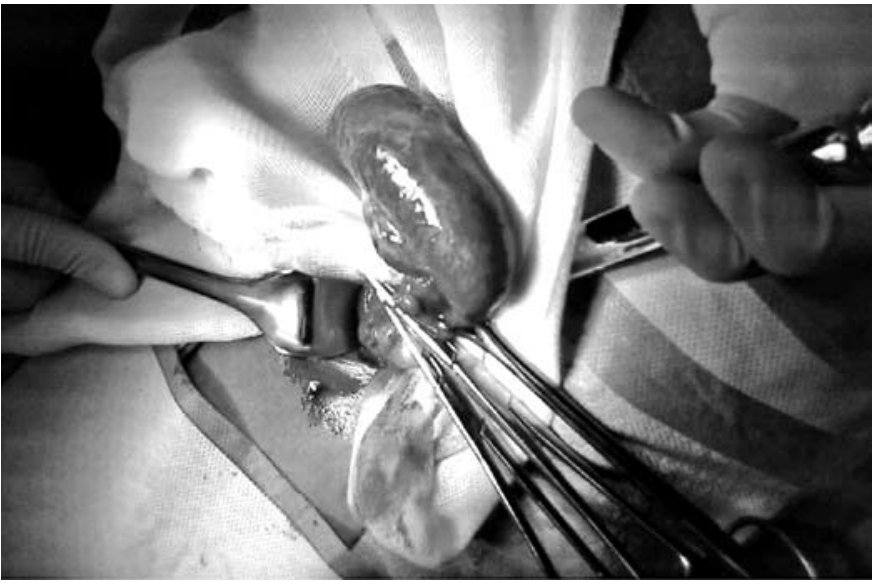

Fig. 2 Fotografía de la pieza extirpada

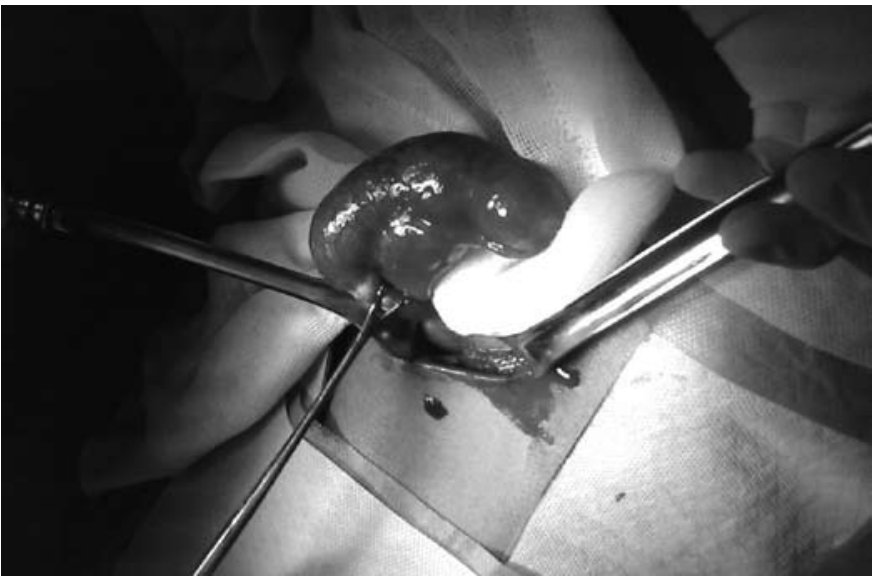

Fig. 3 apéndice con mucocele y apendicitis aguda

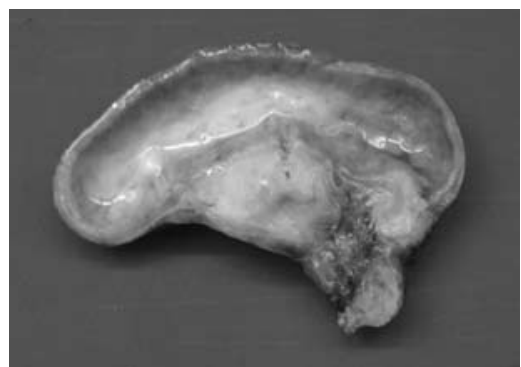

Fig. 4 Corte sagital del apéndice cecal. La luz está dilatada y ocupada por material mucoso incoloro

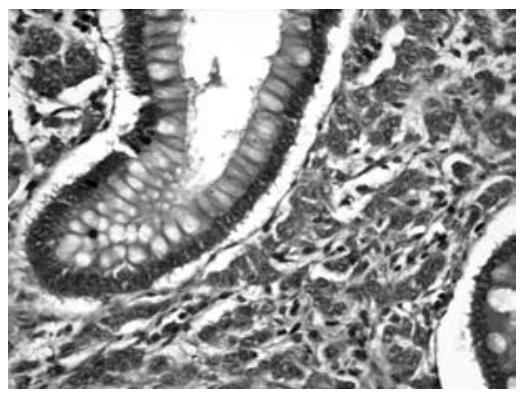

Fig 5: Revestimiento mucosecretor de la superficie de la mucosa

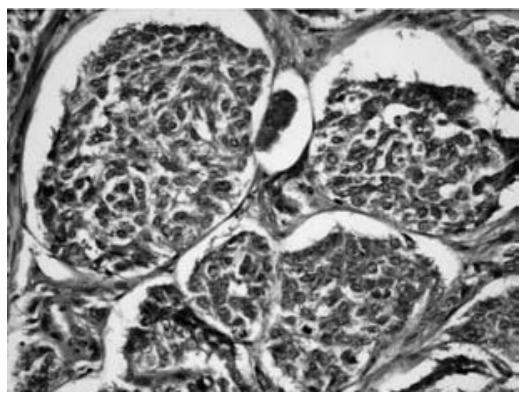

Fig 6: Patrón organoide: nidos sólidos de células enterocromafines.

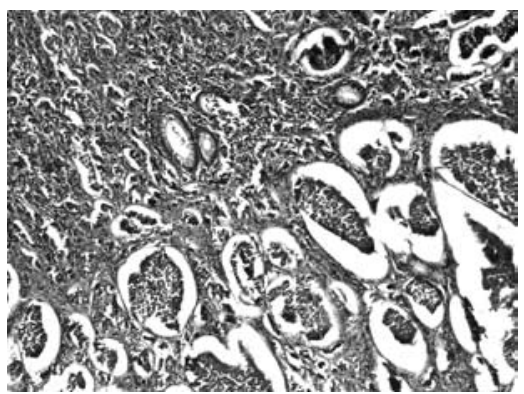

Fig 7: Nidos sólidos delimitados por bandas de tejido conectivo 